\title{
Is a single dose of meningococcal serogroup $C$ conjugate vaccine sufficient for protection? experience from the Netherlands
}

\author{
Patricia Kaaijkk ${ }^{1,4^{*}}$, Arie van der Ende ${ }^{2}$, Guy Berbers ${ }^{3}$, Germie PJM van den Dobbelsteen ${ }^{1}$ and Nynke Y Rots ${ }^{1}$
}

\begin{abstract}
Background: The first meningococcal serogroup C (MenC) conjugate vaccine was licensed in 1999 and introduced in the United Kingdom. Countries that have implemented the MenC vaccine since then in their national immunisation programmes use different schedules. Nevertheless, all involved countries seem to experience substantial declines in the incidence of MenC disease.

Discussion: Since 2001, the MenC conjugate vaccine has been implemented in the Netherlands by offering a single dose to all children aged 14 months. Prior to the introduction of the vaccine into the national immunisation programme, a catch-up vaccination campaign was initiated in which a single dose of the MenC conjugate vaccine was offered to all children aged from 14 months up to and including 18 years. Since then, there has been no report of any case of MenC disease among immunocompetent vaccinees. Administration of a single dose of MenC conjugate vaccine after infancy could be beneficial considering the already complex immunisation schedules with large numbers of vaccinations in the first year of life. The present paper deals with the advantages and critical aspects of a single dose of the MenC conjugate vaccine.

Summary: A single dose of MenC conjugate vaccine at the age of 14 months in combination with a catch up vaccine campaign appeared to be a successful strategy to prevent MenC disease in the Netherlands, thereby confirming that a single dose of the vaccine could sufficiently protect against disease. Nevertheless, this approach can only be justified in countries with a relatively low incidence of serogroup $C$ meningococcal disease in the first year of life. Furthermore, a good surveillance programme is recommended for timely detection of vaccine breakthroughs and outbreaks among non-vaccinees, since long-term protection after a single dose in the second year of life cannot currently be guaranteed.
\end{abstract}

\section{Background}

Neisseria meningitidis is a major cause of invasive bacterial infections worldwide [1]. The highest incidence rate of meningococcal serogroup $\mathrm{C}$ (MenC) disease is in children aged 2 years or younger and in the age group of 14 to 20 years [2]. Efforts to control infections with $N$. meningitidis have been aimed at the development of effective meningococcal vaccines and subsequent implementation in appropriate vaccination schedules. In 1999, an efficacious conjugate vaccine against MenC disease,

\footnotetext{
* Correspondence: patricia.kaaijk@rivm.nl

${ }^{1}$ National Institute for Public Health and the Environment (RIVM), Centre for infectious Diseases Control Netherlands, Section Vaccinology, Bilthoven, the Netherlands

Full list of author information is available at the end of the article
}

consisting of serogroup C capsule polysaccharide conjugated to tetanus toxoid as carrier protein, has been licensed in Europe and has been used widely ever since. However, in the absence of randomised controlled trials on efficacy that support a specific vaccination schedule, each country has its own scheme with respect to the MenC conjugate vaccine (Table 1) [3]. In general, regardless of the vaccination schedule that has been followed, all countries that implemented the MenC conjugate vaccine in their programme experienced substantial declines in the incidence of MenC disease [4]. At present, not all European countries have implemented the MenC conjugate vaccine in their national immunisation programmes, such as Scandinavia, and most Eastern European countries. For the countries that have

\section{Biomed Central}


Table 1 Current vaccination schedules with the MenC conjugate vaccine in European countries

\begin{tabular}{|c|c|c|c|}
\hline Country & $\begin{array}{l}\text { Number of } \\
\text { doses }\end{array}$ & Current MenC vaccination schedule & Source \\
\hline Andorra & 3 & 2,4 , and 18 months & $\mathrm{WHO}^{\mathrm{a}}$ \\
\hline Austria & 2 & $\begin{array}{l}13 \text { months (MenC) and } 11-13 \text { years } \\
\text { (MenACWY) }\end{array}$ & The Federal Ministry of Health, Austria ${ }^{b}$ \\
\hline Belgium & 1 & 15 months & WHO \\
\hline Cyprus & 1 & 12-13 months & $\mathrm{WHO}$ \\
\hline France & 1 & $12-24$ months & Ministry of labour, employment and health, France ${ }^{c}$ \\
\hline Germany & 1 & $11-23$ months & WHO \\
\hline Greece & 3 & 2,4 , and $15-18$ months & WHO \\
\hline Iceland & 2 & 6 and 8 months & WHO \\
\hline Ireland & 3 & 4,6 , and 13 months & WHO \\
\hline Italy & 3 & 3,5 , and $11-12$ months and risk groups & WHO \\
\hline Luxembourg & 1 & $\geq 13$ months & WHO \\
\hline Monaco & 1 & 2 years & WHO \\
\hline Netherlands & 1 & 14 months & WHO \\
\hline Portugal & 3 & $3,5,15$ months & WHO \\
\hline Slovenia & - & risk groups & WHO \\
\hline Spain & 3 & $2,4-6,12-18$ months & $\begin{array}{l}\text { Vaccine Advisory Committee of the Spanish Association of } \\
\text { Paediatrics }^{d}\end{array}$ \\
\hline Switzerland & 2 & $12-15$ months and $11-15$ years & WHO \\
\hline $\begin{array}{l}\text { United } \\
\text { Kingdom }\end{array}$ & 3 & $3,4,12-13$ months & Department of Health, United Kingdom ${ }^{e}$ \\
\hline
\end{tabular}

${ }^{a}$ http://apps.who.int/immunization_monitoring/en/globalsummary/scheduleselect.cfm

bhttp://www.bmg.gv.at/cms/home/attachments/1/4/0/CH1100/CMS1038913010412/impfplan_2011.pdf

chttp://www.sante.gouv.fr/IMG/pdf/Tableau_des_vaccinations_recommandees_chez_les_enfants_et_adolescents.pdf

${ }^{d}$ http://vacunasaep.org/profesionales/calendario-de-vacunaciones-de-la-aep-2011

ehttp://www.dh.gov.uk/prod_consum_dh/groups/dh_digitalassets/documents/digitalasset/dh_122401.pdf

included MenC vaccine in their programme, the most commonly used vaccination schedules are 2 doses in first year of life and a booster in the second year of life or 1 dose in the second year of life with possibly an additional booster later in life. The present paper deals with the advantages and critical aspects of a single dose of the MenC conjugate vaccine in the second year of life with the experience of the Netherlands as example.

\section{Discussion}

Implementation of MenC vaccination in the Netherlands In the Netherlands, the increase in MenC disease in 2000-2002 was the reason to implement the MenC conjugate vaccine into the Dutch immunisation programme (Table 2). In 2000, 105 patients (an annual incidence rate of 0.7 per 100.000 inhabitants of the Netherlands) with a culture-proven serogroup $\mathrm{C}$ meningococcal infection were reported and in 2001 this number increased to 276 patients (an annual incidence rate of 1.7 per 100.000 inhabitants of the Netherlands). In the Spring of 2002, just prior to the implementation of the MenC vaccine into the immunisation programme, a vaccination campaign was initiated including all children aged from 14 months up to and including 18 years was started. Subsequently, the MenC vaccine, i.e. a conjugated MenC vaccine with tetanus toxoid as carrier protein, was introduced for children at the age of 14 months into the immunisation programme of the Netherlands from September 2002 onwards.

During this vaccination campaign approximately 3.5 million vaccinations were given, which together with the vaccinations given prior to the campaign resulted in a vaccination rate of $94 \%$ of the target population. At present, the vaccination rate among children receiving a single MenC conjugate vaccine dose at the age of 14 months according to the Dutch immunisation programme has been reported to be as high as $\geq 95 \%$ (birth cohort 2007) [7].

\section{Outcome of MenC vaccine implementation in the Netherlands}

In the Netherlands, surveillance of MenC disease is performed by a central laboratory that receives nation-wide meningococcal isolates from more than $90 \%$ of all cases with invasive meningococcal disease. Strikingly, since the introduction of MenC conjugate vaccine in the Netherlands there has been no report of any case of MenC disease among immunocompetent vaccinees (Table 2). In addition, the MenC disease incidence among non-vaccinees showed a clear reduction due to 
Table 2 MenC disease cases ${ }^{\mathrm{a}}$ in the Netherlands per year, age group, and among vaccinees

\begin{tabular}{|c|c|c|c|c|c|c|c|c|c|c|c|}
\hline Year & Total & Incid & nce rate ${ }^{b}$ & & & Age group & & & & & \\
\hline & & & $0-11$ mths & $1-4$ yrs & $5-9$ yrs & $10-14$ yrs & $15-19$ yrs & $20-24$ yrs & $25-29$ yrs & $\geq 30$ yrs & among vaccinees \\
\hline 2000 & 105 & 0.7 & 2 & 22 & 15 & 11 & 18 & 9 & 4 & 24 & n.a. \\
\hline 2001 & 276 & 1.7 & 23 & 50 & 27 & 39 & 65 & 15 & 9 & 48 & n.a. \\
\hline $2002^{c}$ & 222 & 1.4 & 13 & 39 & 30 & 26 & 47 & 17 & 5 & 45 & $0^{c}$ \\
\hline $2003^{d}$ & 42 & 0.3 & 11 & 6 & 0 & 1 & 0 & 6 & 0 & 18 & 0 \\
\hline 2004 & 17 & 0.1 & 1 & 1 & 1 & 0 & 0 & 1 & 2 & 11 & 0 \\
\hline 2005 & 4 & 0.03 & 0 & 0 & 0 & 0 & 0 & 0 & 0 & 4 & 0 \\
\hline 2006 & 4 & 0.03 & 0 & 1 & 0 & 0 & 0 & 0 & 0 & 3 & 0 \\
\hline 2007 & 9 & 0.06 & 2 & 0 & 1 & 0 & 1 & 1 & 0 & 4 & 0 \\
\hline 2008 & 11 & 0.07 & 2 & 0 & 0 & 0 & 0 & 0 & 1 & 8 & 0 \\
\hline 2009 & 10 & 0.06 & 1 & 1 & 0 & 0 & 1 & 0 & 2 & 5 & $0(1)^{\mathrm{e}}$ \\
\hline 2010 & 6 & 0.04 & 2 & 0 & 0 & 0 & 2 & 0 & 0 & 2 & $0(1)^{\mathrm{e}}$ \\
\hline
\end{tabular}

Surveillance data 2000-2009 are obtained from annual reports "Bacterial Meningitis in the Netherlands" published by "Netherlands Reference Laboratory for Bacterial Meningitis" [5]. Data from 2010 are not published yet

n.a.; not applicable

${ }^{a}$ MenC disease cases are defined as culture and/or PCR-proven presence of MenC bacteria in cerebrospinal fluid and/or blood

${ }^{b}$ Incidence rate is defined as the annual incidence rate of MenC disease per 100.000 inhabitants of the Netherlands

c In the Netherlands, MenC conjugate vaccine was introduced in Spring 2002

${ }^{d}$ The case fatality rate (CFR) calculated from 58 patients with MenC disease cases occurring between January 2003-May 2005 was 5.2\% [6]

e One case of MenC disease occurred in a vaccinated 16 years old female (2009), and one case in a vaccinated 19 years old male (2010). Both persons had an immune disorder

herd immunity. From 2004 onwards, a maximum of 2 cases of MenC disease per year occurred at the age $<1$ year (all infant cases occurred at the age $\geq 6$ months, $<$ 1 year). Apparently, the routine childhood vaccination and the initial catch-up campaign resulted in a reduction of circulating serogroup $\mathrm{C}$ meningococci which in turn has led to a decreased transmission. It is important to note that replacement by meningococci with other serogroups, i.e. serogroup A, B, Y, W135, was not observed. On the contrary, the incidence of serogroup B meningococcal disease decreased from 1998 onwards and continued to decline since the introduction of the MenC conjugate vaccine in 2002 [5]. However, this is considered to be based on coincidence, since the MenC vaccine does not induce cross-reactive immunity to meningococcal serogroup B bacteria. This is confirmed by a study in the United Kingdom, whereby the prevalence of carriage of meningococci associated with serogroup B disease was unaffected by the introduction of the MenC conjugate vaccine [8]. As expected, in this latter study a decline in prevalence of carriage of serogroup C meningococci was reported from 1999, the year of introduction of MenC conjugate vaccine in UK. This finding was consistent with the observed herd immunity in the non-vaccinated teenage population in the UK [8].

\section{Duration of immune response afforded by MenC vaccine implementation in the Netherlands}

Recently, MenC-specific immunity before and after implementation of the MenC conjugate vaccine in 2002 in the Netherlands has been analysed using two large cross-sectional serum banks each obtained from a nation-wide Dutch population [9]. These serum banks contain samples from participants 0-79 years of age that were collected in two cross-sectional serosurveillance studies performed in 1995/6 and 2006/7 [10,11]. From these serum banks, polysaccharide specific IgG concentrations against serogroup $\mathrm{C}$ meningococci and functional antibody titers obtained with the SBA have been determined and described earlier [9]. Here we show the SBA titres from respectively 735 and 1220 serum samples before and after the introduction of the MenC conjugate vaccine (Table 3). These data illustrate that, more than 4 years after vaccination (serum bank 2006/7), the MenCspecific SBA titres were still remarkably high (SBA geomean titre $(\mathrm{GMT}) \geq 8$ ) in individuals who were vaccinated at the age of 5 year or older during the vaccination campaign (aged 9/10 years in 2006/7) (Table 3). A single MenC conjugate vaccine administration above 5 years of age seems to induce persistent protective SBA antibody levels, gradually increasing with age of vaccination. In contrast, MenC-specific SBA levels in serum samples from individuals that have been vaccinated against $\mathrm{MenC}$ disease at the age of 14 months, i.e. according to the Dutch routine immunisation programme, showed a rapid decline within a few years after vaccination. Apparently, high functional antibody levels against serogroup $\mathrm{C}$ meningococci persist longer in persons who were vaccinated at an age of 5 year or older [9].

These findings are consistent with results from a study in the United Kingdom, showing that 5 years after 
Table 3 Serum bactericidal antibody (SBA) titres from serum samples obtained before and after the introduction of the MenC conjugate vaccine [9]

\begin{tabular}{|c|c|c|c|c|c|c|}
\hline \multirow[t]{2}{*}{ Age } & \multicolumn{3}{|c|}{ Pre-introduction MenC vaccine (1995/6) } & \multicolumn{3}{|c|}{ Post-introduction MenC vaccine (2006/7) } \\
\hline & No. samples & SBA-GMT $(95 \% \mathrm{Cl})$ & $\%$ samples $\mathrm{SBA} \geq 8$ & No. samples & SBA-GMT $(95 \% \mathrm{Cl})$ & $\%$ samples $\mathrm{SBA} \geq 8$ \\
\hline $0-7$ mths & 3 & $2(\mathrm{NA})$ & 0 & 59 & 2 (n.a.) & 0 \\
\hline 8-14 mths & 13 & $2.1(1.9-2.4)$ & 0 & 62 & $2.4(1.9-3.0)$ & 3.2 \\
\hline 15-24 mths & 18 & $2.0(\mathrm{NA})$ & 0 & 27 & $131.3(64.5-267.5)$ & 92.6 \\
\hline 2 yrs & 24 & $2.0(\mathrm{NA})$ & 0 & 42 & $13.1(8.3-20.8)$ & 61.9 \\
\hline $3-4$ yrs & 42 & $2.1(1.9-2.4)$ & 2.6 & 106 & $5.4(3.8-7.7)$ & 30.2 \\
\hline $5-6$ yrs & 34 & $2.8(1.6-4.7)$ & 6 & 49 & $5.2(3.4-7.8)$ & 28.6 \\
\hline $7-8$ yrs & 43 & $3.4(2.2-5.2)$ & 11.2 & 56 & $5.1(3.7-7.1)$ & 33.9 \\
\hline $9-10 y r s^{a}$ & 27 & $3.0(1.3-6.9)$ & 11.3 & 73 & $9.4(5.8-15.2)$ & 45.2 \\
\hline $11-12$ yrs & 31 & $2.5(1.4-4.5)$ & 8.4 & 72 & $20.0(12.4-32.2)$ & 61.1 \\
\hline $13-14$ yrs & 34 & $5.6(2.1-14.8)$ & 23.5 & 65 & $23.5(15.9-34.6)$ & 69.2 \\
\hline $15-16$ yrs & 38 & $3.3(2.1-5.1)$ & 16.3 & 55 & $57.9(36.7-91.1)$ & 81.8 \\
\hline $17-18$ yrs & 25 & $3.6(1.8-7.1)$ & 11.7 & 43 & 89.8 (58.4-138.0) & 86 \\
\hline $19-21$ yrs & 21 & $2.6(1.9-3.5)$ & 5.9 & 88 & $159.6(109.1-233.4)$ & 95.5 \\
\hline $22-25$ yrs & 38 & $6.2(3.1-12.4)$ & 26.1 & 104 & $4.2(9.1-22.6)$ & 49 \\
\hline $26-30$ yrs & 56 & $4.6(2.1-10.0)$ & 24.5 & 69 & $4.2(3.1-5.9)$ & 26.1 \\
\hline $31-39$ yrs & 66 & $4.7(3.8-5.8)$ & 22.5 & 58 & $3.6(2.1-6.0)$ & 19 \\
\hline $40-49$ yrs & 65 & $5.3(4.0-6.9)$ & 26 & 49 & $4.1(2.5-6.7)$ & 20.4 \\
\hline $50-59$ yrs & 59 & $4.5(3.9-5.2)$ & 19.2 & 52 & $4.1(2.5-6.6)$ & 21.2 \\
\hline $60-69$ yrs & 51 & $5.9(3.0-11.5)$ & 29.5 & 54 & $3.2(2.7-3.7)$ & 18.5 \\
\hline 70-79 yrs & 48 & $3.6(2.1-6.1)$ & 17.1 & 37 & $3.6(2.5-5.4)$ & 21.6 \\
\hline Total & 736 & $4.3(3.3-5.5)$ & 19.7 & 1220 & $10.2(8.9-11.7)$ & 43.0 \\
\hline
\end{tabular}

n.a.; not applicable

95\% Cl; 95\% confidence interval

${ }^{a}$ Individuals who were vaccinated at the age of 5 year during the vaccination campaign are aged 9-10 years in 2006/7

vaccination children vaccinated at an age of 10 years or older exhibited higher functional (SBA) antibody levels against serogroup $\mathrm{C}$ meningococci compared to younger children [12]. Although, at present SBA is the best correlate of protection for evaluating the immune response to meningococcal serogroup $C$ vaccines, for long-term protection SBA levels alone may not be ideal [13]. A better predictor for long-term protection may be a combination of SBA levels with the number of MenC-specific memory B cells [14]. At present, failures of longterm protection in children immunised with a single dose of MenC conjugate vaccine at the second year of life have not been documented [3]. The question that thus remains is whether the existing antibody response and/or B cell memory response in the individuals vaccinated with a single dose at the age of 14 months will be strong enough to prevent disease in case of exposure to serogroup $\mathrm{C}$ meningococci at later ages. High SBA levels may be necessary, because meningococci have the potential of rapid multiplication leading to fast progression of MenC disease $[15,16]$. This is probably why some countries (i.e. Austria and Switzerland) have implemented a booster dose at adolescent age in addition to the vaccine dose in the second year of life (Table
1). So far, no breakthroughs of MenC disease have occurred in immunocompetent vaccinated individuals in the Netherlands. This is most probably due to diminished circulation of serogroup $\mathrm{C}$ meningococci as a consequence of herd immunity induced by vaccination. On the other hand, it might be that all vaccinated individuals are protected, despite the low SBA levels in those who have been vaccinated at younger ages.

\section{Implementation of the MenC vaccine in other countries MenC vaccination in first year of life}

In 1999, the MenC conjugate vaccine was introduced nation-wide in the United Kingdom as first country in Europe using three different MenC conjugate vaccines. The vaccination scheme of the UK was three doses at infancy, at the age of 2, 3 and 4 months. In Ireland and Spain, similar MenC vaccination schedules were implemented with three doses in the first year of life. In 2006, the MenC vaccination schedule of the UK was altered into the three dose schedule at 3, 4 and 12-13 months of age. This decision was based upon the evidence-based assumption that a booster with $\mathrm{MenC}$ conjugate vaccine in the second year of life is needed to maintain protection against $\mathrm{MenC}$ disease after infancy and that two 
doses for infants is minimally needed for a good priming response $[17,18]$. At present, the vaccination schemes in Ireland and Spain have also been adapted accordingly with two doses of the MenC conjugate vaccine in the first year of life and a third booster dose in the second year of life. A comparable vaccination scheme is implemented in Andorra, Greece and Italy (Table 1). Results from the different immunisation schedules that have been used in Canada revealed that multiple doses in early infancy provides little additional benefit over programmes starting with 1 dose at the age of 12 months [19].

\section{MenC vaccination in second year of life}

At present, apart from the Netherlands, several other countries, such as Belgium, Cyprus, France, Germany, Luxembourg, and Monaco, have implemented a vaccination scheme with a single dose in the second year of life (Table 1). However, this approach can only be justified in countries with a relatively low incidence of serogroup $\mathrm{C}$ meningococcal disease in the first year of life, which was the case in the Netherlands prior to introduction of the MenC conjugate vaccine $(<10 \%$ of MenC disease cases occurred in infancy; Table 2). Recently, Austria and Switzerland have introduced an additional booster dose in teenagers besides the primary single dose in the second year of life. This vaccination schedule anticipates the observed waning immunity found after 1 dose in the second year of life.

The ideal immunisation schedule should aim at a maximal level of effectiveness with a minimum number of doses needed. A single vaccination in the second year of life might be sufficient for adequate protection, whereas a minimum of 2 doses seems necessary when starting in early infancy $[17,18]$. The immune system of younger infants is not fully developed. For example, a conjugated $\mathrm{Hib}$ vaccine induced a significantly lower antibody response at 2-3 months of age when compared to 6 months or later [20]. For this reason, administration of MenC conjugate vaccine after infancy, such as has been implemented in the Netherlands, could be beneficial. In addition, most national immunisation programmes includes already a large number of vaccinations in the first year of life. This makes the introduction of newly available vaccines at infancy, such as against rotavirus, increasingly difficult, while there are still several new vaccines under development for this young age group, such as vaccines against serogroup B meningococci and respiratory syncytial virus.

\section{Summary}

Despite the fact that different schedules have been used for implementing the MenC conjugate vaccine, all involved countries seem to experience substantial declines in the incidence of MenC disease [4]. In the
Netherlands, there has been no report of any case of MenC disease among immunocompetent vaccinees, since the introduction of a single dose of the MenC conjugate vaccine in the second year of life. Although no data on nasopharyngeal carriage rates before and after immunisation are available, it is likely that the combination of this introduction together with the vaccine campaign, in which a single vaccine dose was offered to all children aged from 14 months up to and including 18 years, has led to a major reduction of circulating serogroup $\mathrm{C}$ meningococci. The herd immunity that was established has also led to a significant reduction of serogroup $\mathrm{C}$ meningococcal disease among non-vaccinees. Nevertheless, it had been shown that individuals vaccinated at the age of 14 months with a single dose of the MenC conjugate vaccine showed a rapid decline in (functional) antibody levels against serogroup $C$ meningococci within a few years after vaccination. For this reason, when applying this vaccination scheme, i.e. a single dose in the second year of life without an addition booster dose, it is important to have a solid surveillance programme, in which the number of patients with serogroup $C$ meningococcal disease is carefully being monitored in order to determine long-term vaccine protection. This will allow timely detection of vaccine breakthroughs and outbreaks among non-vaccinees, making a timely and appropriate intervention possible, such as deciding to administer a booster vaccination when needed to guarantee protection during periods of susceptibility in the second decade of life.

\section{Acknowledgements}

We would like to thank Truus W. de Graaf for providing useful suggestions and relevant information.

\section{Author details}

${ }^{1}$ National Institute for Public Health and the Environment (RIVM), Centre for infectious Diseases Control Netherlands, Section Vaccinology, Bilthoven, the Netherlands. ${ }^{2}$ Academic Medical Centre (AMC), Department of medical Microbiology and the Netherlands Reference Laboratory for Bacterial Meningitis, Amsterdam, the Netherlands. ${ }^{3}$ National Institute for Public Health and the Environment (RIVM), Centre for infectious Diseases Control Netherlands, Laboratorium for Infectious Diseases and Screening, Bilthoven, the Netherlands. ${ }^{4}$ National Institute for Public Health and the Environment (RIVM), Centre for infectious Diseases Control Netherlands, Section Vaccinology, Building A9, Mailbox 41, PO Box 1,3720, BA Bilthoven, The Netherlands.

\section{Authors' contributions}

PK drafted the outline and the text of the manuscript. AE was responsible for the surveillance data of MenC disease in the Netherlands, GB for the sero-epidemiological data of MenC, GD as expert on meningococcal disease provided intellectual content that added to the manuscript and NR highlighted the need for this debate. All authors were actively involved in reviewing the content and editing the text of the manuscript. All authors read and approved the final version of the manuscript.

\section{Competing interests}

The authors declare that they have no competing interests. 
Received: 5 July 2011 Accepted: 8 February 2012

Published: 8 February 2012

\section{References}

1. Gasparini R, Panatto D: Meningococcal glycoconjugate vaccines. Hum Vaccin 2011, 7:170-182

2. Granoff DM, Harrison LH, Borrow R: Meningococcal vaccines. In Vaccines.. 5 edition. Edited by: Plotkin SA, Orenstein WA, Offit PA. Saunders, Elsevier; 2008:399-434

3. Chiappini E, Venturini E, Bonsignori F, Galli L, de Martino M: Serogroup C Neisseria meningitidis invasive infection: analysis of the possible vaccination strategies for a mass campaign. Acta Paediatr 2010, 99:1609-1614

4. Trotter CL, Ramsay ME: Vaccination against meningococcal disease in Europe: review and recommendations for the use of conjugate vaccines. FEMS Microbiol Rev 2007, 31:101-107.

5. Bacterial Meningitis in the Netherlands. Annual reports 2000-2009. [http://www.amc.uva.nl/?pid=8446].

6. de Greeff CS, de Melker HE, Schouls LM, Spanjaard L, van Deuren M: Preadmission clinical course of meningococcal disease and opportunities for the earlier start of appropriate intervention: a prospective epidemiological study on 752 patients in the Netherlands, 20032005. Eur J Clin Microbiol Infect Dis 2008, 27:985-992.

7. Lier van EA, et al: RIVM Rapport 210021011 Vaccinatiegraad Rijksvaccinatieprogramma Nederland. 2010 [http://www.rivm.nl/ bibliotheek/rapporten/210021011.pdf].

8. Maiden MC, Ibarz-Pavon AB, Urwin R, Gray SJ, Andrews NJ, Clarke SC, et al: Impact of meningococcal serogroup $\mathrm{C}$ conjugate vaccines on carriage and herd immunity. J Infect Dis 2008, 197:737-743.

9. de Voer RM, Mollema L, Schepp RM, de Greeff SC, van Gageldonk PG, de Melker $\mathrm{HE}$, et al: Immunity against Neisseria meningitidis serogroup $\mathrm{C}$ in the Dutch population before and after introduction of the meningococcal C conjugate vaccine. PLoS One 2010, 5:e12144.

10. de Melker HE, Conyn-van Spaendonck MA: Immunosurveillance and the evaluation of national immunization programmes: a population-based approach. Epidemiol Infect 1998, 121:637-643.

11. van der Klis FR, Mollema L, Berbers GA, de Melker HE, Coutinho RA: Second national serum bank for population-based seroprevalence studies in the Netherlands. Neth J Med 2009, 67:301-308.

12. Snape MD, Kelly DF, Lewis S, Banner C, Kibwana L, Moore CE, et al: Seroprotection against serogroup $C$ meningococcal disease in adolescents in the United Kingdom: observational study. BMJ 2008, 336:1487-1491.

13. Andrews N, Borrow R, Miller E: Validation of serological correlate of protection for meningococcal $\mathrm{C}$ conjugate vaccine by using efficacy estimates from postlicensure surveillance in England. Clin Diagn Lab Immunol 2003, 10:780-786.

14. Blanchard Rohner G, Snape MD, Kelly DF, John T, Morant A, Yu LM, et al: The magnitude of the antibody and memory $B$ cell responses during priming with a protein-polysaccharide conjugate vaccine in human infants is associated with the persistence of antibody and the intensity of booster response. J Immunol 2008, 180:2165-2173.

15. Snape MD, Kelly DF, Salt P, Green S, Snowden C, Diggle L, et al: Serogroup $\mathrm{C}$ meningococcal glycoconjugate vaccine in adolescents: persistence of bactericidal antibodies and kinetics of the immune response to a booster vaccine more than 3 years after immunization. Clin Infect Dis 2006, 43:1387-1394.

16. de Voer RM, van der Klis FR, Engels CW, Schepp RM, van de Kassteele J, Sanders EA, et al: Kinetics of antibody responses after primary immunization with meningococcal serogroup $C$ conjugate vaccine or secondary immunization with either conjugate or polysaccharide vaccine in adults. Vaccine 2009, 27:6974-6982

17. Borrow R, Goldblatt D, Finn A, Southern J, Ashton L, Andrews N, et al: Immunogenicity of, and immunologic memory to, a reduced primary schedule of meningococcal C-tetanus toxoid conjugate vaccine in infants in the United kingdom. Infect Immun 2003, 71:5549-5555.

18. Joint Committee on Vaccination and Immunisation DoH, England. Proposed changes to the routine childhood immunisation schedule. 2005 [http://www.advisorybodies.doh.gov.uk/jcvi/ childhoodimmunisationoc05.pdf].
19. De Wals $P$, Trottier $P$, Pépin J: Relative efficacy of different immunization schedules for the prevention of serogroup $C$ meningococcal disease: a model-based evaluation. Vaccine 2006, 24:3500-3504.

20. Siegrist CA: The challenges of vaccine responses in early life: selected examples. J Comp Pathol 2007, 137(Suppl 1):S4-9.

\section{Pre-publication history}

The pre-publication history for this paper can be accessed here: http://www.biomedcentral.com/1471-2334/12/35/prepub

doi:10.1186/1471-2334-12-35

Cite this article as: Kaaijk et al.: Is a single dose of meningococcal serogroup $\mathrm{C}$ conjugate vaccine sufficient for protection? experience from the Netherlands. BMC Infectious Diseases 2012 12:35.

\section{Submit your next manuscript to BioMed Central and take full advantage of:}

- Convenient online submission

- Thorough peer review

- No space constraints or color figure charges

- Immediate publication on acceptance

- Inclusion in PubMed, CAS, Scopus and Google Scholar

- Research which is freely available for redistribution 